\title{
Los ensueños en terapia gestáltica
}

\author{
FRANCISCO VÁSQUEZ \\ Departamento Académico de Psiquiatría. Facultad de Medicina, UNMSM
}

\begin{abstract}
RESUMEN
Se describe el ensueño a través de los tiempos y el significado que tiene y tuvo según las épocas y las culturas. Se enfoca la teoría general de los ensueños desde Hipócrates hasta nuestros días, así como su interpretación, tanto del punto de vista psicológico como religioso y cultural. Se hace énfasis en la función terapéutica de los ensueños, tanto en la terapia freudiana como la jungiana y la gestáltica. Reflexiona sobre los aportes de Freud, Jung y Perls, ampliando los conceptos del ensueño de la terapia gestáltica, que considera el ensueño "como el camino real a la integración, siendo la producción humana más espontánea de la existencia. El ensueño es la expresión que nos llega sin intención, voluntad y deseo. El ensueño más absurdo no nos impacta en el mismo momento como algo absurdo, se siente como verdadero. El ensueño es mucho más que un deseo inconcluso, es un mensaje existencial muy claro acerca de lo que falta en nuestras vidas, lo que se evita hacer y vivir". Se ilustra el ensayo con un trabajo de ensueño con una paciente en la Clínica de Día, del Hospital Guillermo Almenara, empleando las técnicas gestálticas. El ensayo se circunscribe a una apreciación de la filosofía y praxis gestáltica sobre los ensueños.
\end{abstract}

Palabras clave: Sueños; terapia de Gestalt; terapia psicoanalítica.

\section{DREAMS AND GESTALT THERAPY SUMMARY}

The dream is described here by in the course of the time and the meaning it has and had according to time and culture. The general theory of dreams is focused from Hippocrates until our days, as well as its psychological, religious and cultural interpretation. Emphasis is made on the therapeutic function of dreams, in the Freudian, Jungian and gestalt therapy. It meditates on Freud's, Jung's and Perls' contributions, enlarging the concepts of dream in the gestalt therapy that considers the dream "as the real road to integration, as the human is but a spontaneous production of existence. A dream is the expression that we receive without intention, will and desire. The absurd dream does not impact us in the same moment as something absurd, but he/she feels it as true. The dream is much more than a not concluded desire, it is a very clear existential message about what is missing in our lives, what is avoided to make and live". The essay is illustrated with a dream work with a patient at the "Guillermo Almenara" Hospital Day Clinic using the gestalt technique. The rehearsal is bounded to an appreciation of the gestalt philosophy and practice on dreams.

Key words: Dreams; Gestalt therapy; Psychoanalysis therapy.

\section{1.- EL ENSUEÑO A TRAVÉS DE LA HISTORIA}

Aunque soñar es un fenómeno natural, ha sido objeto de muchas especulaciones desde la antigüedad hasta nuestros días.

\footnotetext{
Correspondencia:

Dr. Francisco Alfredo Vásquez Palomino

Departamento Académico de Psiquiatría

Facultad de Medicina, UNMSM

Av. Grau 755. Lima 1 - Perú

E-mail:panvas@tsi.com.pe
}

El Talmud de Babilonia precisa que en esa época había en Jerusalén 24 intérpretes oficiales del ensueño. Un día el rey quiso que le interpretaran un sueño y les consultó a todos por un sueño que había tenido y cada uno le predijo un evento diferente. Se encuentra así mismo una mención en la tradición china en el siglo XVIII a.C.

En la época Helénica existían 420 templos de Esculapio donde se practicaba la incubación (que consistía en dormir en el templo hasta obtener un sueño, permitiendo la cura de la enfermedad). Se dormían envueltos con piel sangrante de cabra ofre- 
cida en sacrificio a los sacerdotes; mientras tanto, grandes serpientes verdes y amarillas de dos metros de largo se deslizaban lentamente en la loza mármol entre pétalos de flores y cuerpos que dormían $\left(^{1}\right)$.

La historia de la interpretación onírica se remonta a unos 3000 años atrás. Con fines didácticos se las clasifica en no psicológicas y psicológicas. Los dos tipos de interpretación onírica han convivido en ocasiones simultáneamente. Como no psicológicas se incluye todas las teorías que consideran el sueño como "mensaje de los dioses", revelación de hechos o fuerzas ajenos a nuestro diario quehacer, como las que se daban en los pueblos primitivos.

Se considera también los sueños mencionados en la Biblia, por ejemplo el sueño de José en relación con la concepción de María, relatado por San Mateo; igualmente importante es la interpretación de los sueños por medio de claves referidos en el antiguo Egipto, el segundo milenio antes de Cristo, en el tratado de los sueños de la India siglo V (a.C.). Como otro ejemplo de la Biblia se considera la interpretación de que hace José del sueño del Faraón sobre las siete vacas gordas y las siete vacas flacas $\left({ }^{1}\right)$.

Las interpretaciones psicológicas se inician con Hipócrates, quien hace una relación entre sueños y enfermedad. Platón menciona la aparición de instintos libres. Aristóteles consideraba que los sueños obedecían a leyes del espíritu humano, aunque los relacionaba con la divinidad y los definía como actividad psíquica en el estado de reposo. Para Freud, el ensueño ya no es un mensaje trascendente de lo alto, sino un mensaje inmanente de abajo, de las pulsiones inconscientes. Los sueños son la vía más directa para llegar a conocer el inconsciente, pues son la realización imaginaria de un deseo prohibido. Considera el ensueño con mucha frecuencia como un "síntoma neurótico". Jung le da un valor más elevado, atribuyéndole no sólo causas psicológicas o biográficas, sino una percepción inconsciente del fondo cultural común de la humanidad. Los sueños se extienden sin descontinuar hacia el porvenir, el ensueño no esconde ningún deseo reprimido, sino al contrario, revela los elementos del inconsciente colectivo y puede revertir en un significado esotérico $\left({ }^{1}\right)$.
Para Jung, el ensueño llena muchas funciones como corrección de la actividad consciente, autorregulación psicológica, anticipación prospectiva; además, percibe que el pensamiento onírico es una forma filogenética anterior de nuestros pensamientos.

\section{2.- SOÑAR EN UN LABORATORIO}

Tenemos tres estados diferentes: vigilia, sueño profundo y el ensueño. El ensueño implica una intensa actividad córtico-frontal derecha, bajo control del sistema límbico (relacionado con las emociones y la memoria) e hipotálamo. Acompañado por el movimiento rápido de los ojos (REM), la mirada bajo los párpados sigue la escena del ensueño.

\section{"Sueño paradójico"}

Es la etapa del sueño con producción de ensueños; sería en realidad más profundo que el sueño llamado "profundo", contrariamente a lo que nos imaginamos con frecuencia.

\section{¿Quién ensueña? y ¿Cuánto?}

Todos ensoñamos; incluso el feto desde el sétimo mes de gestación (antes de haber podido almacenar las percepciones visuales o de reprimir los deseos prohibidos por el "superyo"). También sueñan los ciegos de nacimiento. Soñamos más o menos cien minutos por día, en cuatro o en cinco períodos; aparecen cada hora y media aproximadamente; son cortos al principio de la noche y con duración creciente.

Los bebés sueñan aproximadamente el $50 \%$ del tiempo que duermen, como una labor para terminar los circuitos neuronales. Los adultos sueñan del 20 al $25 \%$ de la noche. Los ensueños disminuyen durante la infancia y la adolescencia y decrecen con la edad avanzada (12 a $15 \%)\left({ }^{1}\right)$.

La mujer embarazada duplica su tiempo del ensueño para "acompañar" al feto y prosigue de este modo hasta la lactancia. Las personas que comparten la misma cama también sueñan con frecuencia al mismo tiempo. 
Pero, por ejemplo, los esquizofrénicos en período de crisis, considerando que ya han delirado mucho durante el día, sus ensueños disminuyen en cantidad, pero son normales en calidad. El alcohol también puede llegar a suprimir el ensueño. Así mismo, los barbitúricos disminuyen los ensueños. El soñar parece indispensable para la supervivencia, más que para el sueño profundo. Todo el mundo sueña, pero no todo el mundo se acuerda de sus ensueños.

Freud estimaba que los ensueños nos sirven, claramente o disfrazados, para realizar un deseo consciente o inconsciente; entonces significaría que si no sueño es que no tengo un deseo no satisfecho; por lo tanto, estoy sano y equilibrado.

Por otro lado, Perls mencionaba que las personas que no se acuerdan de sus ensueños son fóbicos o no tienen el valor de mirar la vida de frente; entonces, no son ni sanos ni equilibrados $\left({ }^{2}\right)$.

Según Claudio Naranjo, algunas de las personas no son capaces de producir más que recuerdos desdibujados de las imágenes de los ensueños a pesar de sus esfuerzos para revivenciarlos; esto es una muestra que indicaría la fuerte tendencia del individuo para alinear el ensueño de su "propia experiencia" $\left({ }^{3}\right)$.

¿Se debe entonces tener algunos ensueños, ni muchos ni demasiados pocos para escapar a estas teorías? Probablemente sería más adecuado el hecho de renunciar a aplicar leyes generales sobre las relaciones entre la frecuencia de los ensueños y el grado de "normalidad".

\section{3.- ¿PARA QUÉ ENSOÑNAMOS?}

El sueño con ensueños permite el registro del material mnésico diurno cargado de emociones; mientras que los recuerdos sin carga emotiva se registrarán durante las fases de SUEÑO SIN ENSUEÑO. Sea lo que sea, es durante la noche cuando se acomodan y se fijan nuestros recuerdos. Según Jouvet, una de las funciones esenciales del ensueño parece ser la reprogramación genética. El ensueño asegura la integración de nuestra memoria individual a nuestra memoria evolutiva.
El psicólogo Binswanger, fundador del Análisis Existencial, afirmaba que había que "despsicologizar al ensueño", dándole su dimensión universal. Así, el ensueño permitiría armonizar mejor el comportamiento social adquirido y el comportamiento instintivo básico.

Por ejemplo, hasta los esquimales sueñan con serpientes, aunque no haya ninguna en su ambiente, lo que coincide con la tesis junguiana de los arquetipos.

Cada noche sería entonces un regreso al manuscrito original con corrección. Sería también el momento del mantenimiento de la red neuronal, de la reparación de los circuitos dañados, de revisión y perfeccionamiento de los circuitos neuronales. Generalmente, los ensueños reciben su "inspiración" de lo vivido en el día o los días precedentes a la noche en que aparecen.

\section{4.- DURACIÓN DEL ENSUEÑO}

El ensueño es propio de las especies superiores. Aparece en animales de sangre caliente, a partir de los pájaros $\left(^{1}\right)$.

Descamps divide a los mamíferos en cazadores y cazados. Los cazados, herbívoros o granívoros, consumen gran parte de su tiempo nutriéndose, duermen poco y ensueñan menos (5\% de su sueño). Los cazadores, carnívoros, se nutren rápidamente, tienen un sueño largo y profundo con una gran parte de sus ensueños (20 a 30\%).

El hombre está programado como carnívoro, 20\% del tiempo está consagrado a los ensueños. Son fundamentalmente ensueños de "agresión y sexualidad". Revisa, entonces, sin cesar sus comportamientos de ataque y seducción, llevado por dos instintos de combate y reproducción.

Entonces, sucedería durante la noche, la reconstitución de estas reacciones antiguamente adaptadas y posteriormente desvalorizadas hasta la destrucción por la cultura diurna.

Fuera del ensueño hay dos vigilias: la del estado de vigilia, propiamente dicha, destinado a las actividades del individuo socializado; y la del ensueño 
destinado a la especie, que permite la reproducción periódica de los esquemas de la raza, por una intensa actividad cerebral imaginaria, mientras que el resto del cuerpo está inhibido por un poderoso mecanismo de bloqueo químico.

"El ensueño puede entonces ser considerado como una muralla contra la cultura, por su vuelta periódica a lo instintivo".

\section{5.- ENSUEÑO, DESEO SEXUAL Y ANGUSTIA}

"El aumento del ensueño paradójico (o tiempo de sueño) en la mujer durante la segunda mitad del ciclo ovárico, es el punto máximo justo antes de la ovulación correspondiente al pico de secreción de testosterona, que excita el deseo en la mujer. Cualquier ensueño se acompaña de excitación genital: congestión del clítoris en la mujer y erección en el hombre, en más de $60 \%$ de los casos" ${ }^{1}$ ).

La erección precede a la aparición del ensueño en más o menos 2 minutos y se mantiene 10 a 20 minutos, tanto en el recién nacido como en el anciano, como más evidente en los períodos de ensueños de la mañana; que es también más largo (36 minutos en promedio versus 10 minutos al principio de la noche) y es al parecer independiente del contenido explícito del ensueño.

La privación prolongada del ensueño provoca, después de aproximadamente cinco días:

- Aparición de delirio paranoide y sexual.

- Irritabilidad.

- Comportamiento bulímico.

- Hipersexualidad.

Las pesadillas (que afectan a 4\% de la población adulta) rara vez ocurren en período REM (período normal de sueños), al igual que el sonambulismo.

\section{6.- FUNCIÓN TERAPÉUTICA DEL ENSUEÑO}

El ensueño tiene función terapéutica natural y directa, función que no implica por otro lado necesariamente su recuerdo consciente. Habitualmente el ensueño se olvida muy rápido, 8 minutos poste- riores al final de la fase "paradójica"; sólo el 5\% se acuerda haber soñado cuando despierta.

Actualmente se admite que un ensueño, cuanto más cargado emocionalmente, es más censurado y mal recordado, lo que no le impide jugar su papel de autorregulación interna. Freud habría subrayado que los sueños tienen un poder de curación de alivio.

Jung los definió como agentes terapéuticos que corrigen una falta de conciencia, pero que también activan una tendencia latente. El ensueño nos permite liquidar parcialmente las tensiones diurnas; el ensueño paradójico "desomatiza la angustia" (Fisher), tiene una función de autorregulación de las tensiones psicoafectivas internas, una función catártica y traumatolítica que consiste en "digerir" los traumatismos por un "entrenamiento" inconsciente, la confrontación de las situaciones estresantes $\left({ }^{4}\right)$.

Sería particularmente cierto en los casos de los ensueños repetitivos. "La reactivación de las situaciones traumáticas tendría la finalidad de mejorar su elaboración", como lo sugiere Picat. La repetición de los ensueños sirve para atenuar, y así como para borrar definitivamente, el halo afectivo que envuelve a la huella mnémica de la situación estresante. En tanto este conflicto interno no sea resuelto, el ensueño que lo expresa tendrá la tendencia a repetirse.

Los ensueños de una misma noche se encadenan. Si despertamos a un sujeto en cada uno de sus sueños al cabo de 10 minutos, percibimos que toda la noche tiene el mismo sueño (Puede variar las circunstancias, pero el tema permanece idéntico).

\section{7.- TEORÍA GENERAL DE LOS ENSUEÑOS}

Aunque el soñar es un fenómeno natural, ese proceso ha sido objeto de especulaciones desde tiempos antiguos; ello se refleja en cada hipótesis conceptual sobre el mundo y el sistema de vida que se vivía en aquella época.

La historia de la interpretación onírica data desde hace tres mil años y se la clasifica para fines didácticos en "no psicológica y psicológica". En la primera categoría se incluye todas las teorías que 
consideran el sueño como un mensaje, revelación de hechos o fuerzas ajenas a quien sueña. Ambos tipos de interpretación onírica se han dado simultáneamente, como sucede en la actualidad, pues las investigaciones en esta área son amplias y heterogéneas y las clínicas especializadas en el tratamiento de los sueños se convierten en una necesidad. Así mismo, la bibliografía sobre el poder adivinatorio y mágico de los ensueños no ha disminuido.

En las interpretaciones "no psicológicas", se destacan las que daban los pueblos primitivos. Los indígenas relacionaban los ensueños con el mundo demoníaco de su mitología. En esta línea de pensamientos se hallan los ensueños mencionados en la Biblia.

Igualmente importante es la interpretación de ensueños por medio de claves, lo que facilita un significado específico de cada elemento.

"Las interpretaciones psicológicas se inician con Hipócrates, y no como muchos autores que consideran a Freud como el iniciador de la investigación de los ensueños. Desde el punto de vista clínico, Hipócrates hace referencia a la relación entre ensueños y enfermedades. Platón menciona la aparición de nuestros instintos libres durante el sueño. Aristóteles consideraba que los ensueños obedecían a las leyes de nuestro espíritu humano, aunque la relacionaba con la divinidad y los definía como actividad psíquica que tenía lugar durante el estado de reposo" $\left({ }^{1}\right)$.

Los ensueños han sido un campo de interés para diversos autores del campo psicológico y antropológico; se menciona la obra de Jean Piaget "Juego, Sueños e Imitación" (1962), donde se observa que los niños tienen ensueños a partir de una edad aproximada de dos años. En el área de la antropología, Roger Bastido hace referencia en "El Sueño, el trance y la locura".

Los ensueños han sido explorados más que la fantasía y la meditación o que los estados hipnagógicos, y su producto es más claro y dramático que estos otros estados. Al soñar nos olvidamos que estamos fantaseando, creando imágenes de que estamos haciendo cuadros y voces. La fe que tenemos en esa fantasía, la creencia de que es la realidad, se presenta como la única dificultad. Se sabe muy bien que cuando se sueña se toma la fantasía por realidad, se toma la situación más absurda como real; y cuando despertamos, empezamos a ver lo absurdo, lo irracional que es todo, por lo que entonces olvidamos que la realidad en el ensueño es una realidad con significado mucho más profundo del que pueda reconocer la lógica.

Los ensueños han sido utilizados en diversas épocas de la historia por médicos, brujos, religiosos y psicoterapeutas. Con el correr de los años, las religiones fueron abandonándolos, hasta que apareció Freud con su libro "Interpretación de los sueños". Aún hoy son pocos los psicoanalistas y psicoterapeutas que mantienen interés en ellos, pues la mayoría centra su atención en la conducta manifiesta y observable en el paciente $\left({ }^{5}\right)$.

Ensoñar es algo natural, de alguna forma necesario, y que refleja la homeostasis o el ajuste dentro de los procesos mentales mismos y en un nivel superior el ajuste dentro de los propios significados psíquicos en la vida del individuo.

Los ensueños y la concepción psicoanalítica: Freud afirmaba que los ensueños no son la expresión de una actividad cerebral fragmentaria, son susceptibles de entender, traducir e interpretar, como cualquier expresión o síntoma, o manifestación de lo que ocurre en una persona. El mérito que tuvo fue el de introducir definitivamente en el ambiente médico y "científico" la noción de que las expresiones psíquicas o emocionales eran parte, de expresión, de signos y síntomas de lo que está ocurriendo a la persona. Una vez que se llegaba a la interpretación completa de un ensueño, se nos revela esto, como una realización de deseos.

Ya Freud se refería a que Aristóteles creía hallar en los ensueños la indicación del comienzo de una enfermedad de la que en estado de vigilia aún no experimentaba indicios, y autores médicos han aceptado el valor de los ensueños como anunciadores de enfermedad. Distintos a estos ensueños son los que representan la muerte de un pariente querido, produciéndonos sentimientos muy dolorosos; su sentido es el que aparece manifiesto o sea de que muera la persona a la que se refiere. Agrega además que los deseos que el sujeto nos muestra realizados no son siem- 
pre deseos actuales; pueden ser pasados, agotados, olvidados y reprimidos, a los que sólo por el resurgimiento en el ensueño se atribuye supervivencia $\left({ }^{6}\right)$.

Cuando se sueña sintiendo profundo dolor en la muerte de algún familiar cercano, no se utilizará este ensueño como demostración de que el sujeto desea que ocurra tal cosa. La teoría del ensueño se contenta con deducir lo que alguna vez deseó en su infancia; sin embargo, esta limitación no tranquiliza a los que han tenido ensueños de este género y negarán la posibilidad de haber albergado alguna vez esos deseos con la misma fuerza con que afirman no abrigarlos actualmente.

El modelo psicoanalítico propuesto por Freud para descubrir el contenido latente del ensueño, deja de lado las observaciones anteriores, los posibles mensajes (organísmicos) o de otra naturaleza, ya que privilegia las ideas. La asociación libre con relación al contenido aparente del ensueño, ya que toda asociación libre está orientada por la historia personal, con las deformaciones que se sabe son inevitablemente repetidas.

Sin Freud, tal vez jamás nos hubiéramos ocupado de buscar diferentes caminos para desentrañar el mensaje de los ensueños, habiéndose beneficiado poco de su trabajo; lo contrario sucedió con Jung, que no especuló sino investigó los ensueños de sus pacientes y de sus amistades.

Nana Schnake encuentra un gran parecido entre el enfoque gestáltico y lo descrito por Jung. "Esta concepción ve en los fenómenos oníricos un proceso de compensación (hechos biológicos); y se compensa la situación consciente que los vió nacer". Además, cuando es vital para la conciencia que se amplifique un elemento inconsciente, esto ocurre $\left({ }^{7}\right)$.

"Si se toma en cuenta que Jung trabajó sobre 67000 ensueños con sus pacientes y colaboradores, antes de intentar teorizar sobre ellos, sus observaciones y comentarios son muy importantes" $\left({ }^{8}\right)$.

Jung insistió desde el inicio de sus trabajos en el aspecto compensador, así como una clara acción autorreguladora de los mecanismos psíquicos de los mismos. Ejemplos de ello son los ensueños en los que hay un humor alegre y colorido en situaciones reales de tristeza o a la inversa, ensueños de los grises, tristes o "reducidores" del ego en momentos en que la persona vive en situaciones de éxito o de expansión del ego.

Compara la acción de los ensueños a la autorregulación y defensa del organismo frente a las infecciones o heridas o cualquier trastorno que pone en marcha los medios de defensa propios de la persona.

Finalmente Jung se refiere -en oposición a la opinión freudiana que considera al ensueño como la realización de un deseo- conjuntamente con A. Maeder, que el ensueño es una autointerpretación espontánea y simbólica de la situación actual del inconsciente. Añade también que la vida del hombre está llena de un conjunto de polaridades, como el día y la noche, el nacimiento y la muerte, la alegría y el sufrimiento, el bien y el mal, y que no se tiene la seguridad de que uno de los contrarios triunfará sobre el otro; ésta es una continua lucha en la que se encuentra el ser humano, que de no realizarse la vida se interrumpiría $\left({ }^{8}\right)$.

\section{LOS ENSUEÑOS EN TERAPIA GESTÁLTICA}

La terapia gestáltica es un enfoque existencial que no se ocupa únicamente de tratar síntomas o estructuras de carácter, sino mas bien de la existencia total de la persona; y es en los ensueños donde está más claramente expuesta la existencia y los problemas de la existencia.

Freud llamó a los ensueños La Vía Regia, el camino real al inconsciente, en oposición con Perls, que los considera como el camino real hacia la integración, la producción más espontánea que tenemos; nos llegan sin intención, voluntad o deseo. El ensueño es la expresión más espontánea de la existencia del ser humano, no hay nada más espontáneo como el ensueño. El ensueño más absurdo no nos impacta en el mismo momento como algo absurdo, se siente como verdadero. Los ensueños no están sujetos a algún tipo de control o interferencia deliberada; constituyen una obra de arte, donde siempre existe movimiento. Todas las partes del ensueño constituyen fragmentos de la personalidad. Debemos reposeer estas 
partes proyectadas de la responsabilidad, es decir, el potencial escondido que aparece en el ensueño $\left(^{6}\right)$.

El ensueño es una excelente oportunidad para encontrar los hoyos de la personalidad. Aparecen como vacíos, espacios huecos y al acercarse a ellos viene la confusión y el nerviosismo, la experiencia espantosa, la exceptuación, la nada. Éste es el impasse, donde evitamos; viene la fobia, somnolencia. Es mejor trabajar los ensueños con alguien que nos pueda mostrar nuestra evitación. Entender un ensueño significa darse cuenta de lo que evita y el peligro estriba en que la otra persona puede llegar al rescate muy pronto, decir lo que ocurre, en vez de dar la oportunidad de que uno mismo lo descubra.

El ensueño es mucho más que un deseo inconcluso, es un mensaje existencial muy claro acerca de lo que falta en nuestras vidas, lo que se evita hacer y vivir. También en los ensueños hay bastante material para ser reasimilado y reposeer nuestras partes alienadas. Estos mensajes pueden llevar a la comprensión del argumento de nuestra vida, de nuestro karma, de nuestro destino. Lo importante es que cuando asumimos la responsabilidad del argumento de nuestra vida, de nuestros ensueños, somos capaces de cambiar nuestra vida y crecer.

"Según la terapia gestáltica, en los ensueños aparecen las partes alineadas de nuestra personalidad, las partes que rechazamos de nosotros mismo; y, al revivir los ensueños en el presente, se integran esas partes que rechazamos, formando parte integral de la personalidad; en consecuencia, todas las diferentes partes del ensueño son fragmentos de nuestra personalidad que al unirlos favorecen nuestra integración. Perls considera que para el psicoanálisis los ensueños son un juego intelectual; los divide en partes y por medio del significado asociativo, los interpreta, lo cual es fuente de esclarecimiento en la dinámica conflictiva del individuo" $\left({ }^{9}\right)$.

Adriana "Nana" Schnake dice haber visto personas que han tenido verdaderas transformaciones trabajando un ensueño, siguiendo las técnicas gestálticas; en esta situación han estado más presentes que en horas de terapias; sus rostros se iluminan, se les ve vivos; sin embargo, el trabajo psicoanalítico de los ensueños es más encubridor que revelador, así como más teorizante y de este modo nos aleja del mensaje útil. Si se admite que todo lo que ocurre en los ensueños tiene que ver con nosotros y que los personajes, objetos, sonidos o colores son aspectos de nosotros mismos no reconocidos, y con honestidad tratamos de enfrentarnos a ellos, descubriremos mucho de lo que somos nosotros mismos. Agrega que en los ensueños se muestra con más claridad su mensaje; sin embargo, la mayoría de las veces ello no está obvio y por eso que el trabajo de Perls es de gran importancia y no puede ser realizado por alguien recién iniciado en esta técnica $\left({ }^{7}\right)$.

El objetivo y compromiso de la terapia gestáltica es el de lograr suficiente integración de la persona, sin pretender con ello resolver todos sus conflictos de una vez y para siempre. No se intenta completar o cerrar todas las situaciones que no resolvimos en el pasado, hasta el momento de la confrontación; pero sí procura con cada una de sus intervenciones cerrar pequeñas configuraciones, puesto que la vida es un proceso constante y continuo de abrir y cerrar situaciones. Este ciclo o cierre final de situaciones llega en la vida solamente con la muerte.

La terapia gestáltica no es individualista, pues tiende a lograr una mejor relación interpersonal; al trabajar con personas (aun sea individualmente) que tienen dificultades serias con seres cercanos (padres, hermanos, abuelos, etc.), se logra alcanzar no solamente al sujeto con el que trabaja sino además a otras personas que componen su ambiente, quienes en el caso de los ensueños contribuyen o puedan contribuir a los conflictos que surgen en los mismos. En la inter-relación terapeuta-cliente de la terapia Gestalt, el primero se sirve de la noción del espacio-temporal del "aquí y el ahora", reflejada en la conducta del segundo, con el fin de ayudar a éste a comprenderse mejor a sí mismo. Esta toma de conciencia que llega al cliente le permite a su vez llegar a conocer mejor a los demás. Nos damos cuenta que este trabajo permite verificar en la práctica la importancia de la "toma de conciencia" (awareness) en el proceso terapéutico de la terapia Gestalt. Es de suma importancia que el sujeto con el que se trabaja perciba las sensaciones (nivel emocional y sensorial), por medio de sus propias vivencias o actuaciones, lo que está viviendo en el "aquí y el ahora". 
Esta toma de conciencia ayuda a la persona a estar más consciente de sí misma, a estar más alerta, a conocerse mejor, a sentir su propia importancia, a respetar lo que es, lo que puede ser y especialmente aprender a tomar responsabilidad por sí misma $\left(^{3}\right)$.

"La terapia Gestalt considera al hombre como una unidad de elementos físicos, emocionales cognoscitivos sexuales y espirituales. El ser humano funciona adecuadamente cuando todos estos elementos se encuentran integrados y él tiene plena conciencia de ellos. Dentro de una filosofía de la terapia Gestalt se encuentra la aceptación del self, de uno mismo, lo que equivale a tomar responsabilidad de lo que uno es y hace" $\left({ }^{9}\right)$.

"En los últimos años de su vida, Perls dedicó más tiempo a trabajar con los ensueños más que con otro proceso psicológico, según consta en una obra Gestalt Therapy Verbatim, que enfoca exclusivamente el trabajo con ensueños y que fue escrita en base a cassettes grabados en sesiones correspondientes a talleres sobre ensueños, los que fueron reproducidos durante el tiempo que Perls permaneció en el Instituto Esalen de Big Sur California (1964-1969)" ( $\left.{ }^{9}\right)$.

Al ser la terapia Gestalt un enfoque existencial, no se limita a tratar la sintomatología o la estructura del carácter del cliente, sino que además considera la existencia total del ser humano. Esa existencia y su problemática se encuentran especialmente localizada en los ensueños, pues éstos contienen los mensajes de nuestra propia existencia, que, como ya dijimos, expresan situaciones conflictivas, inconclusas, vacíos, necesidades y partes desintegradas de la personalidad.

Ese proceso terapéutico finaliza en la práctica gestáltica, cuando el individuo llega a poseer suficiente fortaleza como para lograr por él mismo su propio crecimiento, cuando aprende a darse cuenta dónde se sitúa su propio crecimiento, cuando aprende a darse cuenta de dónde se sitúan sus propios vacíos existenciales. Perls considera que no se aprende de las palabras; el aprendizaje reside en descubrir, siendo la toma de conciencia ("el darse cuenta") lo que da significado al descubrimiento $\left({ }^{2}\right)$.

Perls llama a los ensueños "el camino real a la integración de la personalidad alienada, la expre- sión más importante de la existencia del ser humano. El ensueño más absurdo deja de serlo en el momento que lo soñamos; en ese momento sentimos que es real".

\section{FUNCIONES DE LOS ENSUEÑOS}

Según la aproximación gestáltica, los ensueños tienen una función compensadora, que representa una autorregulación, que es una función propia del organismo psíquico.

También tendría una función prospectiva, como una forma de anticipación. Muchos de estos ensueños prospectivos tienden hacia una función reductora. Es como si el organismo diera los elementos para que aquello que está en exceso, encuentre su polaridad y su equilibrio.

Se habla también de lo yatrogénico, que se presenta en los ensueños en que se representa la muerte de un ser querido; o ensueños eróticos en situaciones absurdas. El soñante, con el conocimiento de lo psicoanalítico, que ya es popular, se autotortura, se juzga y se llena de sentimiento de culpa y piensa y analiza la relación con la persona en cuestión.

\section{TRABAJO CON ENSUEÑOS}

En el trabajo con ensueños, el terapeuta gestáltico dispone de una serie de técnicas o alternativas: Las más importantes son:

La retroalimentación: Que consiste en recibir una respuesta como un reflejo del propio comportamiento. Esto es a través de la repercusión que sobre otros, la persona aprende algo de sí misma. El primero en servirse de esta técnica psicológica fue Carl Rogers, que la aplicaba al emitir frases él mismo; frases o sonidos que sirven de aprobación a la comunicación que le está transmitiendo a su cliente, o sea a su conducta verbal.

En Gestalt se retroalimenta con la experiencia vivencial, con la parte que vive y siente el cliente en el proceso terapéutico.

Según Perls, quien sueña se proyecta a sí mismo en los ensueños. Así mismo, aportó una gran canti- 
dad de técnicas que sirven para lograr el relato y la elaboración de los ensueños. Con tales técnicas se trabaja un ensueño o un acontecimiento vivido, todo en el "aquí y el ahora", en el presente; no como un episodio del pasado; todo esto permite llegar a la acción sin llegar a la interpretación.

Imaginación: Se trabaja con la fantasía. Las vivencias imaginadas no se interpretan, sino que se integran y se concientizan por medio de la identificación como parte de la misma personalidad. Las fantasías nos hacen concientes de las propias necesidades $\mathrm{y}$, a través de ellas, se puede investigar lo desconocido y tomar contacto con asuntos pendientes, personas no accesibles y sentimientos posesivos de miedo.

Se puede tomar contacto con la fantasía en el trabajo con los ensueños mediante la técnica de la silla vacía o silla caliente, que busca implementar la personalidad y la psicosomática o representación de una escena con los miembros del grupo como actores. A través de la identificación.

Identificación: A través de la técnica del cambio de papeles y de la inversión de roles, identificándose con cada una de las cosas que aparecen en el ensueño. Esta técnica es diferente a la que hacen los psicoanalistas, pues ellos dividen a los ensueños en pedacitos seguido de asociaciones acerca de lo que significa y luego se interpreta. Es posible que con este procedimiento se logre algún significado, aunque por lo general es sólo un ejercicio intelectual; si se quiere lograr algo verdadero en un ensueño, no se debe interpretar, ni jugar juegos intelectuales de introspección, ni asociar ni disociar libre o forzadamente los sueños.

En la terapia Gestalt no se interpreta los ensueños; en vez de analizarlos, trozarlos, se intenta retrotraerlos a la vida, reviviendo el ensueño como si estuviese ocurriendo ahora; se convierte éste en parte de uno mismo, posibilitando un compromiso verdadero; al realimentar situaciones se crea la oportunidad para que el paciente se descubra a sí mismo.

Confrontación: El hecho mismo de entrar en contacto con el terapeuta o el grupo, ya es una confrontación (al paciente se le devuelve su comportamiento como frente a un espejo). La confrontación consiste en la puesta en evidencia de las contradicciones. En el trabajo de la silla vacía y al realizar el cambio de papeles, el paciente se identifica como su interlocutor y así entra en contacto con los aspectos y personas evitados.

También se da a través de interpretaciones verbales y no verbales que realiza el mismo cliente contrastando con su realidad.

En la terapia gestáltica, los ensueños se trabajan como material proyectivo; sin embargo, ésta no es la única modalidad de trabajo con ensueños con Gestalt. Los ensueños nos permiten descubrir el tipo de relaciones interpersonales que establece y los conflictos que mantiene la persona que los sueña. La forma de trabajar los ensueños depende tanto de la personalidad o estilo personal del cliente y del terapeuta. Para lograr extraer el máximo de beneficio al contenido de un ensueño se sigue un proceso sistemático, sin llegar a ser rígido; este procedimiento se resume en tres situaciones $\left({ }^{2}\right)$.

\section{1.- HISTORIA VERBAL DEL ENSUEÑO}

Generalmente se hace una historia de lo que ocurrió la noche anterior o muchas noches antes. No se conserva nada de lo vivido y animado de los procesos del ensueño. El cliente aquí descubre los personajes y objetos que aparecen en el ensueño. Además, ubica el ensueño e indica cómo se sitúa y se percibe a sí mismo en él, cómo percibe a los otros, qué "ve" en su ensueño. Por ejemplo: "Ahora estoy en lo alto de una tapia", "me veo", "o me veo deslizándome por una montaña rusa, a mi lado hay otra mujer que ..."

\section{2.- VOLVER EL ENSUEÑO A LA VIDA}

En terapia Gestalt se logra esto por medio de un giro gramatical. Pedimos al paciente que nos relate un ensueño en tiempo presente que describa la experiencia de su ensueño, como si ocurriera en el mismo momento que lo relata, como si el ensueño fuera la realidad presente y siempre en primera persona: "estoy en este momento viendo a un hombre agachado haciendo un agujero en el suelo". Si deseamos mejorar este proceso aun más para que el 
paciente pueda conectar el argumento de su vida con la experiencia de su ensueño, hacemos que el paciente intercale la declaración "y ésta es mi existencia", después de cada oración. De esta manera, los clientes podrán conectar los mensajes de sus ensueños con el argumento de su propia vida, percibiéndolo. Uno dirá: "Nada en el océano, ésta es mi existencia", "No puedo encontrar un lugar en qué descansar, ésta es mi existencia", "siento como si me hundiera, ésta es mi existencia”.

No importa si se trabaja un trozo del ensueño, o un ensueño antiguo; siempre se le puede recordar, el sueño está vivo y disponible y seguirá conteniendo una situación inconclusa, una situación no asimilada. Cuando se trabaja con los ensueños, se toma por lo general un trozo de él; se puede obtener mucho aun de sólo un fragmento pequeño.

\section{3.- DRAMATIZAR EL ENSUEÑO}

El cliente entra en acción, en movimiento, se convierte en el director de sus propias escenas, es decir, hace de su ensueño una historia o una pieza teatral, se encarga del elenco y de la utilería, va de un lado a otro y monta escena, describiendo dónde se encuentran todas las cosas y personas. Se hace una lista de todos los detalles del ensueño, situaciones, lugares, personas y cosas del sueño; luego se toma cada cosa, cada lugar, persona o estado de ánimo, de preferencia lo fóbico, olvidado, evitativo, y se trabaja sobre ello, convirtiéndose en cada una de esas cosas, sea lo que sea en el sueño; se tiene que convertir realmente en la cosa, inclusive adoptando formas físicas similares, usando su imaginación para ello. "Se olvida la mente y despierta a sus sentidos”. Cada trozo es parte de puzzle, que entero formará un todo más grande - “una personalidad más fuerte, más feliz, más completamente verdadera", según expresa Perls en su obra Sueños y Existencia.

Enseguida se toma cada uno de esos objetos, caracteres y partes, permitiéndoles tengan encuentros entre ellos y escriban un guión; esto quiere decir que sostengan un diálogo entre las dos partes opuestas. Por lo general se empieza riñendo entre ellas, en especial si se trata de opuestos correctos. Todas las partes diferentes (cualquier parte del ensueño es parte de uno) son una proyección de uno mismo y, si hay lados inconsistentes, contradictorios y si se les usa para luchar entre ellos, se tendrá el eterno juego del conflicto y autotortura. Al avanzar el encuentro y el diálogo, hay un aprendizaje mutuo, hasta que se llega a un entendimiento, a una apreciación de las diferencias y se logra la integración de las dos fuerzas opositoras. Se puede observar cómo los pacientes se vuelven más reales, se descongelan al reintegrar las partes de ellos mismos que se han fracturado en el proceso de socialización y que antes no eran aceptadas por nosotros mismos.

Al dramatizar se exagera lo soñado. En esta fase, el cliente se involucra emocionalmente, siente lo que está reviviendo (lo que antes se vivió en el ensueño que tuvo) y permanece en el presente, en el concepto gestáltico del "aquí y el ahora", reidentificándose con los trocitos dispersos de su personalidad que permanecieron juntos superficialmente por la expresión del yo. Cuando todo comienza a marchar, el plan vital, la fuerza de la vida comenzará a fluir de nuevo hacia su centro y el paciente empezará a ser el mismo.

Al llegar a esta tercera fase del trabajo con ensueños, al revivirlos pueden surgir sentimientos, emociones y acontecimientos que el cliente puede evitar, porque pueden representar amenaza para su existencia. Sin embargo, una vez que el cliente expone lo que se imagina no puede soportar, tiene el recurso de prescindir de aquello que evita y de arriesgarse a la experiencia.

No siempre se trabaja un ensueño montando toda una escena, sino que basta con decirnos a nosotros mismos "yo soy un auto chico", "yo soy un bus" etc. Y dejarnos sentir cómo es nuestra existencia siendo aquel objeto y rápidamente se capta lo más singular del mensaje de nuestro ensueño.

Sólo cuando una persona se ha "metido" entera, en ser una caja cerrada y vacía o un objeto decorativo, un tarro de basura o un preservativo desechable, y ha metido todo lo limitado y "falible" que hay en el mismo y ha aceptado la angustia de ese límite, es capaz de ver el endiosamiento y la omnipotencia con que combate esto y ha logrado tener energía para defender su existencia. Aunque fuera algo perecedera y débil, logra darse cuenta de que en él hay un ser 
real y único con determinación a ser lo que es y aceptar con satisfacción su existencia.

Se entiende todo lo que se habla y todo lo que se hace. No se necesita una comprensión especial de los términos. Cuando un paciente trabaja un ensueño, va asumiendo con todo su cuerpo la posición y discurso de lo que es; nos damos cuenta que algo ocurre en esa persona; se percibe el desarrollo de la situación que el paciente vivencia en el permanente cambio expresivo durante el diálogo. Signos fenomenológicos, como la voz, el tono, la expresión, postura, sudor de manos u otras partes del cuerpo, los movimientos musculares, gestos, tic nerviosos, sensaciones y emociones son de vital importancia y de una coherencia tal que años de entrenamiento con el mejor dramaturgo no produciría "actores" de esa calidad; el terapeuta debe de estar atento a ellos, ya que permiten al paciente tomar conciencia o darse cuenta de ellos, llegando al final al contacto con él mismo. Según Perls "lo esencial de la terapia gestáltica reside en que lo no verbal es siempre más importante que lo verbal. Las palabras mienten y persuaden; la postura corporal, la voz, la conducta no verbal es siempre cierta” $\left({ }^{2}\right)$.

Muchos críticos y escépticos del trabajo gestáltico suponen un alto índice de histrionismo en los pacientes y la posibilidad de que todo sea una "actuación”. Lo que no tendría que preocupar demasiado; puesto que sería maravilloso que la gente pudiera actuar el estar bien con la misma frecuencia con que actúa el estar mal.

En la representación de roles, cosas o personas aparecidas en el ensueño nos permiten llegar a la apreciación o a la identificación de la situación total del cliente. Con ello se logra contrarrestar la autoalineación; y, al reidentificarse el paciente, es capaz de transformarse, modificarse y aceptarse en el presente; se conecta de nuevo, las cosas empiezan a salir bien, se recupera lo enajenado por medio de la reidentificación. Aquí se presenta un hecho de difícil comprensión, el de la palabra "Yo" no corresponde a la persona, sino que es un proceso de identificación. Muchas tribus nos llevan ventaja, en ellas no existe la palabra yo, el niño no tiene un yo estructurado, el yo no tiene identificación simbólica. También el hecho de cambiar físicamente de lugar y pos- tura al representar cada cosa es importante y permite vivenciar lo positivo y negativo que hay en ser objeto o persona que apareció en nuestro ensueño.

Perls señala que cuando en un sueño uno es perseguido por un ogro y se convierte en el ogro, la pesadilla desaparecerá, se recobrará la energía invertida en el ogro. La fuerza del ogro ya no estará afuera alienada, sino que estará dentro de uno, donde puede usarse.

El terapeuta gestáltico y los ensueños: Al trabajar con ensueños, Perls recomienda apartarse de las racionalizaciones y argumentos, puesto que una de las funciones del terapeuta gestalt es ayudar a que cada individuo crezca y distinga la realidad de la fantasía. De ahí la importancia que se concede a reconocer cuándo y cómo funciona una proyección, para así optar por seguir el rol que más convenga al crecimiento de cada persona. Se puede decir que al trabajar con ensueños el terapeuta gestalt se convierte en un catalizador, facilita la percepción del cliente y ello se logra al estar alerta el terapeuta de lo que existe en el presente, de la conciencia del mismo. Así es que frustra todos los intentos de evasión que el individuo intente.

Con respecto a la posición del terapeuta Gestalt, Perls recomienda que cada uno sea responsable de sí mismo, de sus actuaciones y de sus pensamientos.

En resumen, la labor del terapeuta Gestalt se centra en facilitar la integración y la reconciliación de las partes opuestas de la personalidad, llamadas polaridades, utilizando para ello la fantasía, la cual es necesaria para crear situaciones, escenarios, personajes y elementos que puedan representar las partes alienadas del ensueño.

En los ensueños encontramos todo lo necesario, ya sea en su perímetro o en su ambiente. La dificultad existencial, la parte que falta a la personalidad, están todas en el ensueño. De algún modo es un ataque frontal a la esencia de la propia no existencia.

Lo que no advertimos con claridad suficiente es que a veces se dedica la vida entera a un ensueño: un ensueño de gloria, de ser útiles, de hacer el bien, de ser bandidos o cualquier cosa. Y en la vida de muchas personas, a través de la autofrustación, nuestros 
ensueños se tornan una pesadilla. Siempre estamos representando roles en el teatro de la vida, se decide "éste es un amigo", "éste es un enemigo" y se juega todos los juegos, hasta que llega el momento en que se despierta a los sentidos; en ese momento comenzamos a sentir, a vivenciar nuestras necesidades y satisfacciones, en vez de jugar roles de necesitar toda clase de utilería-casas, automóviles, docenas de trajes; todas estas pertenencias se nos da por un tiempo limitado, pues no se lo puede llevar con uno; y, si se tiene dinero, entonces se tiene preocupaciones adicionales sobre qué hacer con el dinero. Todo ello constituye los ensueños y pesadillas típicas de nuestra civilización. La idea de despertar y hacerse de verdad, significa existir con lo que se tiene, con el potencial real y pleno, una vida rica y una experiencia profunda. Éste es el significado de una terapia verdadera, de una maduración verdadera: el verdadero despertar, en vez de una continua autodecepción y fantaseo con metas imposibles, sintiendo lástima de uno mismo porque no se puede representar la parte que queremos representar.

Perls estima que los ensueños son una creación única de quien los sueña y son un intento para hallar una solución a una paradoja aparente; en la vida cotidiana del neurótico, sus paradojas también permanecen desintegradas. Es importante para lograr encontrar el significado de los ensueños que el individuo descubra el sentido de la paradoja, reviviendo el ensueño, vivenciando, experimentando todos los elementos que contiene su ensueño.

También en los ensueños se encuentra resistencias a experimentar o vivir ciertos hechos, lo que puede indicarse por el uso constante de verborreas, que se las utiliza mostrando síntomas o bien evitándolos. Todo ello hace que el paciente invierta una gran energía, por pretender salirse del estatus, en especial del "aquî", que la gestalt considera como el elemento fundamental. Si habitualmente no se recuerda los ensueños, puede suceder que se esté negando la confrontación o el enfrentamiento a los problemas cotidianos de nuestra existencia, uno se niega a encarar lo que está mal y evita luchar con asuntos desagradables. Generalmente estas personas son fóbicas y piensan o creen que más o menos han llegado a arreglárselas con la vida. Se sueña, pero no se re- cuerda. Uno ensueña por lo menos cuatro ensueños cada noche. En estos casos, cuando la persona dice no soñar, se utiliza una técnica que consiste en verbalizar con motivación: "ensueños dónde están, ¿por qué no vienen a mí?”. Esto se hace con el objetivo de descubrir las objeciones que tiene el sujeto para no recordar sus ensueños. Otra técnica para recordar los ensueños consiste en que la persona se diga a sí misma, antes de acostarse: "esta noche no voy a soñar; ocurra lo que ocurra no voy a soñar".

En las situaciones en las que un ensueño se interrumpe en el transcurso de la noche y la persona se levanta sobresaltada, es posible que esta interrupción sea una forma de evitar o de no querer aceptar la situación que se diría si se siguiese soñando. Se genera angustia como resultado de alejarse del ahora.

En cuanto a los sueños repetitivos, la terapia Gestalt los considera como resultado de una configuración incompleta; por lo tanto, un ensueño repetitivo es un intento que realiza el individuo para resolver su problemática. Esta posición de la terapia Gestalt va más allá de la creencia freudiana, que considera los ensueños repetitivos como una manifestación obsesiva, compulsiva, producto del instinto de muerte (tanatos). Perls afirmaba que esos ensueños (del instinto de muerte) eran los más importantes, los que más material podían aportar de la vida de la persona. Tales ensueños repetitivos se convierten en pesadillas que tienen un mensaje vital; le están diciendo a la persona repetidamente algo que la persona no escucha. El ensueño repetitivo se termina cuando la persona comprende lo que se está transmitiendo. Mientras una persona está más fragmentada, más carácter de pesadilla tendrán sus ensueños. Siempre es bueno mirar lo que se evita en el ensueño; después se puede llenar los vacíos.

"El ensueño siempre es un mensaje críptico; si fuera un mensaje abierto no habría la necesidad de soñarlo. Entonces uno sería honesto, estaría sano y cuerdo y no se puede ser honesto y neurótico al mismo tiempo" $\left({ }^{2}\right)$.

Los ensueños finalmente guardan algunas semejanzas con las psicosis. Ambos parecen absurdos para el que los ve de afuera y parecen reales para la persona afectada. Mientras se sueña, el ensueño 
parece absolutamente real. El ensueño más absurdo, terrible, no conlleva ninguna duda sobre qué realmente es eso, lo que ocurre en el sueño.

Una diferencia interesante entre los ensueños y la conducta y mentalidad del psicótico es que habitualmente el psicótico ni siquiera intenta enfrentarse con sus frustraciones; simplemente las niega y se comporta como si no existiese. En los sueños, sin embargo, se ve un intento de sobreponerse a ellos, sobre todo si consideramos que la mayoría de los ensueños son pesadillas en las que se frustra a sí mismo. En la medida que uno insiste en el trabajo sobre ensueños, se llega a resolver las autofrustraciones y se aprende a luchar con ellas.

La metodología de la terapia gestalt, aplicada a los ensueños, facilitó que los sujetos entraran en contacto con su parte rechazada, al aceptar integrar aquellos sentimientos, emociones y conductas que se habían transformado en una parte no integrada de ellos mismos. Los sujetos viven su problema, lo sienten y con ello logran entrar en contacto consigo mismos y su medio ambiente, todo ello se logra al sentir sus cuerpos y emociones. Las personas descubren sus tensiones musculares y aprenden al mismo tiempo a permitir que su cuerpo entre en acción; de esa forma se abre el camino para que ocurra el cambio.

A pesar de todo lo formulado, una persona puede llegar a trabajar sus ensueños siguiendo los pasos que se indica a continuación:

1. Diga el ensueño en primera persona, tiempo presente, como si Ud. lo estuviera soñando en este momento.

2. De todas las partes del ensueño, ¿qué parte considera que se parece menos a Ud.? ¿Qué parte está más alienada a Ud.? ¿Cuál es la parte con la que Ud. encuentra más dificultad para identificarse?

3. Cuando lo identifique, vuelva al ensueño, haciendo hablar dicha parte en primera persona y en presente.

4. Ahora piense: ¿Recibió algún mensaje de su ensueño? ¿Hay algo en su ensueño que reconoce en Ud.?

5. Cuando reciba algún mensaje, ponga su ensueño en la "silla vacía" y exprésele su agradecimiento y gratitud, así como cualquier otra cosa que Ud. desee comunicarle.

\section{TRABAJO DE CAMPO $\left({ }^{10}\right)$}

Para ilustrar el trabajo del ensueño, voy a presentar la historia de una paciente a quien llamaremos Irma. Ella tiene 32 años, limeña, soltera, vive con sus padres y tiene secundaria incompleta. Trabaja como niñera en una "cuna infantil" (dependencia estatal).

$\mathrm{Su}$ enfermedad se inicia 12 años antes de su ingreso a la "clínica de día", teniendo como factor desencadenante un examen ginecológico (según el relato de la paciente), en la cual se siente ansiosa, con trastornos neurovegetativos y temores de salir embarazada. Desde esa fecha tiene mucho temor a los hombres y evita en todo momento de comprometerse o de tener enamorado, pese a ser requerida con frecuencia dado a su aspecto físico atrayente y su carácter simpático. Desde esa fecha ha cambiado continuamente de trabajo evitando las relaciones interpersonales duraderas; hasta conseguir un trabajo donde sólo trata con niños.

Tres meses antes de su ingreso es requerida en amores por un pariente que llega como huésped a la casa de sus padres. Este pariente se enamora de ella y le pide formalizar un compromiso para casarse. Irma se siente atraída por su pariente, pero cada vez que está cerca de él siente mareos, sensación nauseosa, trastornos neurovegetativos y obnubilación de conciencia, predominando una angustia constante, que le da la sensación que va perder la razón, que va a desmayarse. Razón por la cual es internada en nuestro servicio.

A la entrevista se encuentra una paciente bien orientada, tanto alopsíquicamente como autosíquicamente, colaboradora histriónica, pueril, evasiva, con una marcada fachada histérica.

Su comportamiento en el hospital de día es inmaduro, evasivo y pueril, tratando en todo momento de relacionarse a un nivel infantil y evitando todo tipo de compromiso y responsabilidad.

A los 15 días de su ingreso, en una sesión de dinámica grupal, Irma refiere que desde hace cerca de 10 años tiene un ensueño que siempre se le repite, "sobre todo cada vez que tiene problemas o que tiene que decidirse por algo". En las últimas sema- 
nas lo tiene casi todas las noches, que le produce mucha angustia, como si fuera una pesadilla.

Vamos a relatar el encuentro con Irma:

Terapeuta.- A ver veamos cómo es tu ensueño.

Irma.- Estoy como en un desierto y de repente veo una cosa grande con una puerta inmensa, muy bonita ...hace bastante frío y yo quiero entrar a la casa, pero no atrevo a llamar por temor de que la gente que vive allí puede ser gente mala .... Cuando estoy por golpear ... me despierto muy asustada ..a veces con mucho frío, temblando y otras veces empapada de sudor.

Terapeuta.- Relata el ensueño en presente, como si lo estuvieras viviendo en este momento.

(La paciente actualiza su ensueño con mucha emotividad y dramatismo).

Terapeuta.- Ahora...representa el rol de la puerta ...es decir, conviértete en puerta, sé una puerta e inclusive adopta físicamente el aspecto de una puerta.

Irma: "Me siento pesada..... pero fácil de caerme .....como si el viento me pudiera hacer caer".

Terapeuta: "Háblale a la chapa.....dialoga con ella". Irma: "Chapa ....introdúceme la llave antes que el viento me traiga abajo".

Terapeuta: "Conviértete en chapa nuevamente y contéstale a la puerta".

Irma: "Yo no puedo abrirte....tiene que ser con llave y yo no la tengo.......alguien tiene que hacerlo".

Terapeuta: "Haz el rol de llave ......conviértete en la llave".

Irma: (Cambia de posición; pero se siente incómoda y prueba varias posiciones hasta quedarse de pie con los brazos en alto sobre la cabeza). "Soy de acero, redonda, de color dorado, dura fuerte.....tengo un adorno y un huequito en el centro".... "Me siento incómoda siendo llave".

Terapeuta: "Háblale a la chapa".

Irma: "Voy a introducirte....para poder abrir la puerta"... "no me apures.....".

Terapeuta: "Vuelve a ser llave".

Irma: "No te pongas dura......" (en estos momentos, Irma abre los ojos apresuradamente y se sonríe, con una mezcla de satisfacción y asombro).
Terapeuta: ¿De que te has dado cuenta?

Irma: (Se queda como bloqueada por unos instantes y luego mirando entre gozosa y avergonzada) dice: "siento como si hubiera estado encerrada....parece que he tratado de buscar salida, de querer que me abran....es decir que me ayuden a buscar una salida.........como si no permitiera que nadie llegue a mí".

¡Aquí se cierra la gestalt!

La paciente posteriormente completó su tratamiento con otros encuentros psicoterapéuticos. Fue dada de alta a los 20 días después del relato de esta experiencia. Su seguimiento en consulta ambulatoria 4 años después nos dio la satisfacción que había logrado superar sus grietas neuróticas existenciales.

Actualmente está casada y tiene dos bebés y su hogar aparentemente se mantiene dentro de los limites y los promedios de las normas sociales y culturales.

\section{COMENTARIO $\left({ }^{10}\right)$}

El relato que hemos presentado nos muestra en forma patente que, en el ensueño de Irma, cada parte de él es parte de ella misma, no solamente las personas sino también cada objeto, cada estado de ánimo, cada cosa que aparece en su ensoñación.

Como podrán darse cuenta, Irma recobró su identificación cuando retrotrae su ensueño a su propia realidad en el "aquí y el ahora”.

En el trabajo del ensueño le permitimos que representara las partes fóbicas del mismo, y en esa forma logró su identificación plena, que es contraria a la alienación; la alienación significa "eso no es mío....Eso no soy yo.... Eso es algo diferente.... Algo extraño... Algo que no me pertenece".

Muchas veces nos encontramos con una fuerte resistencia para representar la parte enajenada; es como si no se quisiera reposeer, recuperar aquella parte de uno mismo, que ha sido empujada hacia fuera por la propia personalidad. De esta forma nos empobrecemos a nosotros mismos; superando este "impasse" al representar todos los roles y crear un argumento, logrando de esa forma la integración. 
Lo importante en gestalt es no interpretar, sino únicamente realimentar las situaciones, creando la oportunidad para que el paciente se descubra a sí mismo. Nuestro relato nos muestra que los ensueños son mensajes existenciales de aquella parte de la personalidad que está fallando; de esa forma podemos ver claramente cómo se evaden los conflictos y los problemas. El ensueño siempre es un mensaje críptico; si fuera un mensaje directo no habría necesidad de soñarlo. Entonces, nosotros estaríamos integrados y honestos, es decir, estaríamos sanos y cuerdos, ya que no se puede estar integrado y honesto y ser neurótico al mismo tiempo.

El ensueño de Irma es el tipo de ensueño recurrente y tal vez son los ensueños más importantes desde el punto de vista existencial. En este caso, el que se repitiera durante muchos años significa que había muchas gestaltes incompletas, conflictos y problemas que no se habían resuelto y por tanto no podía avanzar ni progresar en su vida existencial, frustrándose en forma continua en su conducta social como cultural.

El enfoque conductual o fenomenológico de Irma, indudablemente, es muy variado y rico en especulaciones psicoanalíticas; pero, lo humano y existencial nos presenta una persona inmadura psicosexualmente que no quería asumir compromisos y responsabilidades de las personas adultas.

No olvidemos que crecer significa estar solo y estar solo es un requisito previo para la madurez y para relacionarnos empáticamente con los demás. La soledad en el ser humano sin un anhelo de apoyo es muestra de desarrollo emocional.

En resumen, el ensayo se circunscribe a una apreciación de la filosofía y a la praxis gestáltica sobre los ensueños. Se ocupa brevemente sobre las características psíquicas principales de los ensueños, describiendo en forma muy sucinta la técnica en el trabajo gestáltico.

Se relata un caso de un ensueño recurrente de una paciente soltera, inmadura psicosexual, con dificultad para las relaciones interpersonales; que luego de ser "tratada" gestálticamente recobra su individualidad y enfrenta sus fobias, luego de una terapia gestáltica integrativa, tanto individual como social y cultural, de acuerdo con el sistema de rehabilitación de la clínica de día del hospital "Guillermo Almenara I.".

\section{CONCLUSIONES $\left({ }^{10}\right)$}

1. Los ensueños son mensajes que nos llegan cuando dormimos, son parte integrante de nuestra existencia. Cada noche soñamos, aunque a veces los contenidos son extraños, tienen un sentido profundo en nuestras vidas.

2. Los ensueños en terapia Gestalt son importantes y deben traslaborarse tanto a nivel individual como grupal. En la terapia individual, el paciente actúa los elementos del ensueño que el terapeuta considera que tienen partes importantes de su existencia. En los grupos se trabaja por medio de talleres o maratones de crecimiento; en los cuales también se puede usar la modalidad de intervención individual empleada por Perls y otros terapeutas gestálticos.

3. Los componentes del grupo terapéutico pueden actuar o interpretar personajes o cosas del ensueño que vienen a ser sus personalidades, sentimientos y estilos de vida. Ello permite al individuo integrarse a sí mismo, al comprender que está ocurriendo en la otra persona que trabaja con su ensueño. También el observador del grupo comprueba que una gran parte de los conflictos que el otro relata, se encuentran en él mismo, llegando así a la toma de conciencia y el "darse cuenta".

4. Se habla de trabajo con ensueños, porque la terapia Gestalt es una forma de psicoterapia vivencial o de vivir experiencias; tanto el cliente como el terapeuta tienen que trabajar para resolver los asuntos inconclusos del primero, aunque ello excluye que en algunos casos se resuelvan también los del propio terapeuta.

5. El trabajo con ensueños tiene tres fases: la historia verbal del ensueño, dar la vida al ensueño y dramatizarlo. Al convertirse en diferentes cosas y establecer diálogos entre ellas se construye un guión que constituye un argumento de vida. Al entrar en contacto con estas situaciones o cosas se logra una confrontación con el dolor, con el duelo no resuelto, con la angustia, el odio, etc. Al vivenciar y aceptar estos sentimientos a 
cabalidad se los retrotrae en el presente, en el "aquí y el ahora".

6. En la reidentificación se hace que el paciente represente todas las partes de su ensueño, actuando recíprocamente con todos los papeles y hablando siempre con el Yo (responsabilizándose de lo que dice y de lo que sucede) para volverse a identificar, empleando siempre el tiempo presente para dar vida al drama; así el paciente empezará a reidentificarse con los trozos o pedazos descubiertos de su personalidad, que habían permanecido juntos sólo superficialmente, por medio de la expresión "Yo". Cuando esto empieza a marchar, el élan vital, la fuerza de la vida que ha sido rechazada y evitada y proyectada hacia otros, comenzará a fluir de nuevo hacia su propio centro, y el paciente empezará a ser nuevamente él mismo.

7. En el ensueño se encuentra todo lo necesario, la dificultad existencial y la parte que falta de la personalidad, los llamados hoyos o grietas de la personalidad; estos espacios vacíos que aparecen $\mathrm{y}$, al acercarse a ellos, muchas veces producen confusión y angustia.

8. El ensueño es un mensaje existencial de aquella parte de la personalidad que está fallando, un mensaje de uno mismo a sí mismo. No es directo; si lo fuera no habría necesidad de soñarlo.

\section{APÉNDICE}

1. Todas las personas sueñan en la noche, no solamente una vez sino varias veces.

2. Los bebés sueñan aproximadamente el $50 \%$ del tiempo que pasan dormidos.

3. Los ensueños decrecen durante la infancia y la adolescencia.

4. El promedio del tiempo de ensueños del adulto es de 20 a $25 \%$ de la noche.

5. Los ensueños son cortos al principio de la noche y se hacen más largos a medida que la noche avanza.

6. Los ensueños aparecen cada hora y media aproximadamente.

7. Los ensueños decrecen con la edad avanzada.

8. A la edad de 21 años se ha soñado aproximadamente 113 737 horas o un año y medio (38 325 sueños).

9. A la edad de 40 años se ha soñado aproximadamente 26280 horas o tres años (127 750 sueños).

10. A los 70 años se ha soñado aproximadamente 45990 horas o cinco años y tres meses (127 750 sueños).

11. Ningún sistema de interpretación de ensueños sirve para todos los ensueños. Por lo tanto algunos ensueños son para siempre misteriosos.
12. Solamente quien sueña es la autoridad final del significado de su ensueño.

13.-Mucha gente no recuerda sus ensueños, ello se debe principalmente a la falta de interés en ellos.

14. Muy a menudo los ensueños contienen mensajes que proceden del subconsciente.

15. Generalmente los ensueños reciben su «inspiración» de lo vivido en el día o en los días precedentes a la noche en que se aparecen.

\section{BIBLIOGRAFÍA}

1. Battegay R, Trenkel A. Los Sueños. Barcelona: Editorial Herder. 1972.

a) Schneider PB. Sueños en la teoría y en la práctica del psicoanálisis. Pág. 11-26.

b) Louis V. La interpretación de los sueños y primeros recuerdos de la infancia en la psicología de Adler. Pág.27-52.

c) Fierz HK. Los sueños en la psicología analítica de Jung. Pág.53-70.

d) Armin B. Los sueños en el análisis del destino de Szondi. Pág. $71-110$.

e) Boss M. El sueño y los sueños. Pág.111-42.

f) Burner M. El ensueño dirigido en estado de vigilia. Pág.143-64.

g) Battegay R. Los sueños en la psicoterapia de grupo. Pág.165-82.

h) Trenkel A. Los sueños desde el punto de vista de la práctica clínica. Pág.183-206.

2. Perls F.

a) Sueños y Existencia. Santiago de Chile: Editorial Cuatro Vientos. 1974.

b) Dentro y Fuera del Tarro de Basura. Santiago de Chile: Ed. Cuatro Vientos. 1975.

c) Yo, Hambre y Agresión. México: Fondo de Cultura Económica. 1973.

d) Enfoque Gestáltico. Santiago de Chile: Editorial Cuatro Vientos. 1975.

3. Naranjo C. La vieja y novísima Gestalt. Santiago de Chile: Editorial Cuatro Vientos. 1993.

4. Hall J. La experiencia Jungiana. Santiago de Chile: Editorial Cuatro Vientos. 1986.

5. Van Dusen W. La Profundidad Natural en el Hombre. Santiago de Chile: Editorial Cuatro Vientos. 1993.

6. Freud S. Obras Completas. Madrid: Editorial Biblioteca Nueva Madrid, 1948.

7. Schnacke AN. Sonia Te Envío los Cuadernos Café. Buenos Aires: Editorial Estaciones. 1987.

8. Jung CG. Recuerdos, Sueños, Pensamientos. Barcelona: Editorial Seix Barral. 2001.

9. Stevens J. Esto es Gestalt. Santiago de Chile: Editorial Cuatro Vientos. 1977.

10. Vásquez F. Testimonio de una Comunidad Gestáltica. Tesis Doctoral. Lima: UNMSM. 1986. 